\title{
The Relevance of Feminist Issues: Race, Class, and Sexuality to Maternal Mortality in Ghana
}

Adu J*

Faculty of Health Sciences, University of Western Ontario, Canada

*Corresponding author: Joseph Adu, Faculty of Health Sciences, University of Western Ontario, Canada, Email: Jadu@uwo.ca

Conceptual Paper

Volume 4 Issue 2

Received Date: June 20, 2020

Published Date: August 05, 2020

DOI: $10.23880 /$ whsj-16000143

\section{Abstract}

Globally, women continue to struggle in their quest for gender equality and the right to full participation in society, especially the developing world. In Ghana, it appears the importance of women has largely been considered only in terms of their role as a wife, mother or homemaker rather than in a broad context, where women are considered social partners contributing towards the growth of the country. This has implications for women's autonomy in decision-making in matters vital to reproductive health, including uptake of maternal and child health services. Women's education is crucial in averting the existing social and religious norms to give more voice to women to commensurate their significance in modern society. The government of Ghana has also failed women because of its gender-biased policies. It is recommended that the government of Ghana and policymakers amend their policies to include those that enhance the rights of women and girls, and at the same time eradicate class differences from social justice and human rights perspective. The beneficial consequences will be economic growth and development and reduced rates of maternal and infant mortality in Ghana.

Keywords: Feminist issues; Gender equality; Discrimination; Sexuality; Women autonomy; Maternal mortality in Ghana

\section{Introduction}

Growing up in Ghana and having worked as a male nurse, where there are very few male nurses, I have observed firsthand what gender discrimination means to women in my country. Moreover, as a father of three daughters, I am highly aware of the challenges they will face as teenagers and adults. In Ghana, it appears that the importance of women has been considered only in terms of their role as a wife, mother or homemaker rather than in a broad context, where women are considered social partners contributing towards the growth of the country. Women continue to struggle in their quest for gender equality and the right to full participation in society. While my knowledge of feminist discourse is limited, I have found the chapters of the book, Feminist Issues: Race, Class, and Sexuality by Nancy Mandell in 2009 very interesting and I have erudite a great deal from the readings. I am now able to put them in the context of what I know about these issues in Ghana. Experts in the field of health and social sciences have put forward many factors, including racism and violence against women as the main cause which has been fuelled by patriarchy and sex-gender role discrimination $[1,2]$. For instance, emerging literature have indicated that some men in rural Ghana consider pregnancy and childbirth as women business which has nothing to do men and ironically some women are in full support of this idea with the view that men as heads of the family are breadwinners $[3,4]$.

Women in the past and in recent times have experienced abuse of various forms and have been unwilling to report them, despite the physical and psychological trauma they might have suffered due to their cultural beliefs and race [5]. Work done by various feminist movements have shone light on many challenges women face daily due to the existence of highly patriarchal systems [5,6]. Many feminist theorists, especially the feminists of 'the third wave', aimed to criticize earlier theories which state that gender roles are more biological than social to reduce the supremacy of uncertainty 


\section{Women's Health Science Journal}

between men and women [6].

Most conspicuously in the readings of the first four chapters of the book, is the notion that "Patriarchy" is the cause of all the struggles and suffering of women worldwide. Chapters seven and eleven also support the view that the existing gendered social structures or systems give supremacy to men and are oppressed to women. In order to place a meaningful debate in the context of the readings in feminist issues, this work will be organized using the following concepts: Patriarchy, Gender, Feminism, Heterosexism, and Discrimination.

The first section looks at patriarchy and violence against women, the second section examines gender and women's health, the third section discusses feminism and women's empowerment, while the fourth section presents the concept heterosexism followed by section five which focuses on discrimination against women, and finally the conclusion. These concepts are very relevant to maternal mortality in the sub-Saharan Africa, particularly Ghana due to the inequality experienced by women. This disparity gives more power to men in decision-making, including the care of pregnant women and the place of delivery which has negative implications for maternal deaths [7]. The lack of women's autonomy in making abrupt decisions in matters regarding pregnancy and childbirth could be one of the reasons why women die from preventable maternal complications in Ghana.

\section{Patriarchy and Violence Against Women}

Patriarchy is defined as "a system ruled over by men, whose authority is enforced through social, political, economic, and religious institutions" [8]. Many feminists do not agree with the concepts of patriarchy but vary in their views, especially the radical feminist. Patriarchy is embodied in cultural values, norms, and attitudes that perceive men as powerful in societies which allow them to maltreat women and their female children with all forms of violence or abuse [9]. It is historic that, most societies in the world have been patriarchal with the worst seen in developing countries, including Ghana. The ascendancy of men within the social structures as heads of the family result in expropriating women and undervaluing their work as housewives. Women, therefore, have very few rights in such societies and are constantly subjected to abuses, including intimate partner violence, rape, female genital mutilation, incest, sexual harassments, more $[9,10]$.

The denial of women's rights in their homes and the absence of other viable economic opportunities in the communities' force them to remain in abusive relationships $[11,12]$. This leaves them with physical, psychological, and financial consequences, but traditional patriarchal dogma recognizes male leadership as an expression of power and control which requires women to be submissive than to challenge their husbands. Some of these principles insulate and empower the superiority of men to undermine women's capability to stop their husbands from any wrongdoing $[11,12]$.

Regardless of the vast contribution made by the second and third-waves feminist theorists on the domestic violence, many women today appear to suffer substantially from violence within the household; they are unwilling to report it for fear of breaking up their relationships and being ridiculed, due to the importance of marriage in some societies. For instance, the value placed on marriage in the Ghanaian culture allows women to accept domestic violence, and, therefore, fail to report incidents of violence for fear of divorce [13]. Moreover, women in some ethnic groups or tribes in Ghana are blamed for acts of abuse by their husbands or partners on the hypothesis that they might have done something to deserve it and this deters them from reporting such occurrences for their partners to be reprimanded and corrected [14]. The perpetuation of inhumane acts against women of all ages in Ghana has prevailed for a lengthy period and appears to be heightened in recent times. In some Ghanaian cultures, old women are seen by society as witches and often thrown out of their family homes or ostracized from their communities whereas, old men are considered wisemen and respected by community members. Media reports in Ghana have shown scenes where old women accused of witchcrafts have been stoned to death or ostracized to distant communities designated for witches without any good social amenities [15-18]. That said, women who have contributed to the development of their country are alienated from their communities to face abject poverty and hardship, all because of false accusations, if they happen to survive the violence melted to them when pronounced evil. A more recent occurrence of this inexplicable was the gruesome murder of 90-year-old women in a broad day light by some angry youths, in the Savana region of Ghana, for being the brain behind the lack of development in her community, having been accused by a traditional priest [19].

The classification of power and control in patriarchal societies has dire consequences on maternal health care, more specifically in developing countries, where there are poor health care delivery systems. In accordance with the World Health Organization (WHO), intimate partner violence (IPV) during pregnancy results in fatal adverse health outcomes for both the pregnant woman and her fetus. The physical damage to victim's body and the later physiological effects of stress from current and earlier abuse also affect the development of the baby [20,21]. A clinical study in Africa on IPV against pregnant women reported a prevalence rate 


\section{Women's Health Science Journal}

of $23-40 \%, 3-27 \%$, and $25-49 \%$, respectively for physical, sexual and emotional IPV during pregnancy in Africa [22].

In Ghana, the highly patriarchal systems have deprived women of their entitlement, and, therefore, lack economic power to meet their basic needs, including good nutrition and health care during pregnancy and childbirth. This prevents a substantial number of women from accessing maternal health services even when the services are free, due to lack of money to pay for transportation and other indirect cost. This results in pregnancy-related complications which eventually could result in maternal deaths. It is, therefore, not surprising that Pool, et al. [21] found that violence during pregnancy was associated with perinatal and neonatal mortality in Ghana, with many having life-threatening abortions, and others opting for unsafe abortion in the early stages of their pregnancies to avoid giving birth to children with congenital defects.

\section{Gender and Women's Health}

Western elite feminists consider gender as a distinct from sex arguing that sex is biological, and gender is socially constructed such that sex and gender identities are closely intertwined. That is, gender is not dependent on biology and sex is rooted in genetics and physiology while gender is a process acquired through acculturation [8]. Gender seems to be more complex and nuanced today than it used to be a decade ago, and the social interpretation of gender emerged when society understood the bodily differences in relation to biology [23]. Gender also regulates the differences and types of health problems that affect men and women which have the power to effect changes in health practices and priorities amongst countries worldwide [24].

The physiological differences between men and women could form the basis for the differences in health inequalities among both sexes. This, however, has resulted in the medicalization of normal processes in women. Women's bodies have been considered as a host of disease by medical experts who intervene without adequate risk assessments. This has resulted in increased rates of Caesarian sections, hormonal treatment of symptoms of menopause, and increased dependence on formula feeding instead of breast feeding. These practices have been shown to have serious consequences for women's health and their infants [1].

The use of men's body measurements as standard units for medical practices is another form of gender bias against women since women's body is physiologically different from men. The biological functioning of females with respect to childbearing predisposes some women to various health conditions including postpartum depression, a psychosocial condition which is misconstrued by some medical experts as psychiatric ailment. Women diagnosed with this condition after birth are put on antipsychotic therapy which could affect their personalities in the long run. The failure of health professionals to recognize the social and biological differences between women's body and men, and consider them in decisions on medical diagnosis and prognosis could deepen the existing gender bias. Women are, therefore, seen as vulnerable in all walks of life, but policy makers around the world have failed to offer conditions necessary to improve women's life to reduce the health inequities suffered per their social and biological roles, specifically in the developing world. In spite of their vulnerability, women appear to be more committed to the upbringing of children, especially in rural Ghana. Women living in the hard-toreach areas in Ghana seem to work tirelessly to support their children at the formative stages of life with very strong attachment. In my practice as health practitioner for almost two decades, I can attest to the fact that women are seen more in hospitals, health centers, and clinics any time their wards are sick compared to men. Often times the majority of men are seen in the last days or in the unlikely events that their sick relatives are pronounced dead. The lengthy stay in hospitals and health centers where there are no rest rooms for mothers as well as the heightened anxieties also appears to predispose them to other health-related issues.

\section{Feminism and Women's Empowerment}

Feminism is a broad term that covers a variety of feminist writing which argues in favor of women with respect to gender equality and empowerment. Anderson defined feminism as the societal view of men and women which do not show any biological or natural factor, and thus signifies a link between the daily struggle within a global context [25]. It is also a social/political ideology that seeks to defend the rights of women in all walks of life. Feminism started as a movement to reduce the negative impacts of political systems on women development described as the first, second, and third wave feminist movements. The first wave focused on the right of woman to vote and work shorter hours; the second considered women's emancipation as a goal. The third wave critiqued the lack of inclusion of multiple oppressions faced by women, and focused on social change and intersectionality. These three waves of feminist movement, built on each other's ideology to find equality and recognition for women at the local, national and international platforms which first started in developed countries.

The central theme of the book assigned is on the various feminist theories and movements directed towards social change to reclaim the distribution of power among men and women in society. The first four chapters of the book outline clearly women's struggle since the mid- $19^{\text {th }}$ century when the feminist movements started, and the successes made in 


\section{Women's Health Science Journal}

bridging the equity gap between men and women. Although much has been achieved through the many interactions of feminist scholars and other human rights activists within the United Nations, with emphasis on education of girls and women equitable employment, entry of women in politics, property and marriage rights, much more is needed in the developing world.

The representation of women in politics and leadership positions in Ghana is very low [26,27]. Men outnumber women in parliamentary seats and other political appointments compared to other developing countries and the developed world. For instance, out of 230 members of parliaments in Ghana, only 37 are women, representing $16 \%$ which is far below the United Nations recommendation of $30 \%$ [28]. This could be explained by the lack of resources for women to compete with men for such positions as well as the lack of autonomy on the part of women to make such decisions without the support of their partners. Societal norms also play a major role in deciding who gets the nod as a political leader. Typically, men are more likely to emerge as political heads compared to females in Ghana, even though policy makers have taken cognizant of socio-economic consequences of gender equality.

The role of women in the home as mothers, doing domestic jobs without receiving wages from their husbands contributes to the lack of autonomy on their part to participate in politics. Childbearing on its own could be more than a full-time job depending on how many children one cares for within a household. Women in this situation lack autonomy to make decisions regarding their reproductive life, to improve their wellbeing due to the absence of financial power. The inability of governments and Civil Society Organizations to provide women with basic needs such as free basic education and good health care delivery system clearly informs us that women are still far behind regarding matters of equality and empowerment.

\section{Heterosexism}

Heterosexism is the view that heterosexual relationship is the only normal behavior for men and women. It is considered superior to other forms of sexual orientations (gay, lesbian, bisexual, and transgender). Feminist theories see heterosexism as both an institution and an ideology, a vital element in the maintenance of patriarchy. It perceives men as dominant and aggressive, and women as submissive and passive within the institution of heterosexuality that validates exploitation of women by men [8]. The dominance of heterosexism over other sexual orientations seem to form the basis for the strong activism put forward by the third wave feminists to resist the marginalization of lesbian rights. They have also employed diverse approaches and petitioned political leaders with the Ministry of Education in Canada to include gender and women studies programs in the high school to educate them on women rights regarding their sexuality [6]. These feminist groups, especially belonging to the third wave, have advised women to "take charge of their own sexual lives and put urgency and desire back where it belong" [6]. The international human rights law approves that all persons globally are entitled to enjoy all human rights irrespective of their sexual orientation [29]. Notwithstanding all these gains made by the feminist movements and support by the law, lesbians, and other queer sexual orientations still appear to be suffering some forms of discriminations, even within the developed world with the worst scenarios seem to be occurring in the developing world.

In Ghana, heterosexism seems to take supremacy over all other forms of sexual orientation due to the existing family systems where majority of the people want to have their own biological children. A very small proportion of the population openly declare a different sexual orientation; homosexuality comes under the criminal code of Ghana. It is noteworthy that there are some feminist groups and activists who champion women's empowerment and gender equality, but do not support lesbianism. According to them women and girl's education and their autonomy remains the key for women to take charge of their sexuality in Ghana and other countries in the sub-Sahara Africa.

\section{Discrimination against Women}

Discrimination against women seems to have existed throughout history. It continues to exist despite the Universal Declaration of Human Rights by the United Nations for protecting and promoting the human rights of all persons including women [30]. Discrimination is considered an attitude, behaviour or treatment based on prejudice, and it exists in pay and workplace conditions [8]. Discrimination can also be seen as the "external behaviour that results from prejudice and is also manifested in institutional policies, practices, and laws that deny people their rights or limit their inclusion" [31]. The origin of discrimination against women could be traced through politics, cultural, and religious beliefs, and practices. Discrimination against women appears to take different forms at all levels in society across the world. It could be at the governmental, community or the family level, and this has implications for maternal mortality and economic development. This discussion, however, will be limited to Ghana.

In Ghana, several reports by the Convention on the Elimination of all forms of Discrimination against Women (CEDAW), indicate that the inheritance system is biased toward men and boys. While men have the right of inheritance of lands and property, women can only get such inheritance 


\section{Women's Health Science Journal}

depending on their relationship and the men they have as fathers or husbands [28]. This has contributed to high rates of poverty and indecision among women in most communities. Thus, women lack resources to live, in times of difficulty and this has implications for maternal health outcomes in Ghana [32]. Another instance of discrimination against women in Ghana seems to be the accusations of old women or women as witches compared to old men or men at the community level. Also, it appears to be uncommon for men in rural Ghana to be seen as infertile compared to women who are often accused of childlessness which lead to divorce or their men going into extra-marital affairs.

Another form of discrimination against women in Ghana, which is on the rise is Female Genital Mutilation (FGM); it is very common in the Northern regions of Ghana. FGM is a procedure resulting in partial or total removal of the external female genitalia, or other injury to the female genital organs for non-medical reasons. It is considered a violation of the human rights of girls and women, and normally carried on girls between infancy and age 15 [33,34]. The forbidding practice of FGM is linked to specific ethnic groups and it predisposes victims to various degrees of child birth complications including both maternal and child mortality compared to their non FGM counterparts $[35,36]$. The removal of the clitoris affects the sexual sensitivity of women and leads to decrease in sexual pleasure, painful sex, difficulty in penetration, and absence of orgasm. FGM is also associated with high risk of Caesarean section, post-partum haemorrhage, obstetric tear and prolonged labour which often result in obstetric fistula [37].

Finally, boys are given more opportunities to formal education in the traditional family system in Ghana compare to girls. Poor families support their boy child to go high in education Jones and Chant [38], and this has serious consequences on the maternal health outcomes [39]. That is, the lack of education among rural women coupled with the absence of women autonomy to decision-making in maternal health issues could account for the increased patronage of the services of Traditional Birth Attendance and player camps for obstetric care.

\section{Conclusion}

The six chapters in the assigned book have given me a comprehensive idea of feminists' contribution to gender equality and women empowerment. The five concepts used as a guide for this debate have broadened my knowledge on the struggle that feminist went through to emancipate women around the globe. Feminists movements have played crucial roles in the fight against patriarchy and women abuse in the western world, yet much remains to be done.
Although much progress has been made in achieving gender equality in the developed world, it is somewhat low in the developing world due to high illiteracy rates among women and the existence of highly patriarchal societies. Societal and religious norms in Ghana demand women to be submissive to their husbands. This has contributed to discrimination against women and lack of women autonomy which has consequences for high maternal mortality rate in the country. The government of Ghana has also failed women because of its gender-biased policies. I recommend the government of Ghana and policymakers to revise their policies to include those that enhance the rights of women and girls, and at the same time eliminate class differences from social justice and human rights perspective. This will warrant economic growth and development and reduce the high rates of maternal and infant mortality in Ghana.

\section{Acknowledgment}

I would like to express my profound gratitude to Professor Shree Mulay, Faculty of Medicine at Memorial University of Newfoundland, for her feedback on my earlier draft. Her inputs helped in strengthening this manuscript.

\section{References}

1. Gustafson DL (2010) Underpinnings and Understandings of Girls and Women's Health, Feminist Issues: Race, Class and Sexuality 5: 272-297.

2. Lindsey LL (2015) Gender roles: A sociological perspective. Routledge.

3. Adu J, Owusu MF, Adu I (2020) Socio-Cultural Factors Affecting Pregnancy Outcomes in the Dangme West District of Ghana. Nurs Health Care Int J 4(4): 000224.

4. Ganle JK, Dery I, Manu AA, Obeng B (2016) If I go with him, I can't talk with other women': Understanding women's resistance to, and acceptance of men's involvement in maternal and child healthcare in northern Ghana. Social science \& medicine 166: 195-204.

5. Reece R (2010) Feminist Theorizing on race and Racism', Feminist Issues: Race. Class and Sexuality 5: 87-109.

6. Karaian L, Mitchell A (2009) Third wave feminisms. Feminist Issues: Race, Class and Sexuality, $5^{\text {th }}$ (Edn.), Toronto: Pearson Prentice Hall.

7. Ganle JK, Dery I (2015) What men don't know can hurt women's health: a qualitative study of the barriers to and opportunities for men's involvement in maternal healthcare in Ghana. Reproductive health 12: 93.

8. Gamble S (2000) Routledge Critical Dictionary of 


\section{Women's Health Science Journal}

Feminism and Post-Feminism: London, Gender Identity, preambular paragraph 6 .

9. Rosenberg L, Duffy A (2009) Violence against Women, Feminist Issues: Race, Class and Sexuality 5: 161-196.

10. Therborn G (2004) Between sex and power- Family in the world, 1900-2000. Urry J (Ed.), London and New York: Routledge.

11. Conner DH (2014) Financial freedom: Women, money, and domestic abuse. William \& Mary Journal of Women and the Law 20, pp: 339.

12. Tracy SR (2007) Patriarchy and domestic violence: Challenging common misconceptions. JournalEvangelical Theological Society 50(3): 573-594.

13. Ampofo AA, Okyerefo MPK, Pervarah M (2009) Phallic competence: Fatherhood and the making of men in Ghana', Culture, Society and Masculinities 1(1): 59-78.

14. Amoakohene $M$ (2004) Violence against women in Ghana: A look at women's perceptions and review of policy and social responses, Social Science \& Medicine 59(11): 2373-2385.

15. Bonnie A, Ramana S (2019) Inside the Witch Camp, Metro TV, Ghana.

16. Bruce-Quansah E (2012) Two Brothers Lynch Woman, 75. The Daily Guide, Bolgatanga, Ghana,

17. Mohammed LI (2020) Between Alienation and Belonging in Northern Ghana: The voices of the women in the Gambaga witchcamp, pp: 1-119.

18. Roxburgh S (2018) Empowering witches and the West: the 'anti-witch camp campaign' and discourses of power in Ghana. Critical African Studies 10(2): 130-154.

19. Myjoyonline (2020) 90-year-old woman lynched after traditional priest accused her of witchcraft.

20. WHO (2011) Intimate partner violence during pregnancy. Information sheet, World Health Organization, pp: 4.

21. Pool MS, Otupiri E, Owusu-Dabo E, De Jonge A, Agyemang C (2014) Physical violence during pregnancy and pregnancy outcomes in Ghana', BMC pregnancy and childbirth 14(1): 71.

22. Shamu S, Abrahams N, Temmerman M, Musekiwa A, Zarowsky C (2011) A systematic review of African studies on intimate partner violence against pregnant women: prevalence and risk factors. PloS one 6(3): e17591.
23. Nicholson L (1994) Interpreting gender. Journal of Women in Culture and Society 20(1): 79-105.

24. Public Health Agency of Canada (2003) Population Health- determinants of health, Public Health Agency of Canada.

25. Mandell N (2009) Feminist Issues. Race, Class and Sexuality', $5^{\text {th }}$ (Edn.), Toronto: Pearson Prentice Hall.

26. Asuako J (2017) Women's political participation-A catalyst for gender equality and women empowerment in Ghana. UNDP Ghana. Our Perspective.

27. Odame FS (2010) Ghana Journal of Development Studies 7(1): $1-14$.

28. Laryea JR (2012) The Implementation of the Convention on the Elimination of all Forms of Discrimination against Women in Ghana.

29. International Commission of Jurists (2007) Yogyakarta Principles: The Application of International Human Rights Law in relation to Sexual Orientation and gender identity.

30. United Nations (2014) Women's Rights are Human Rights. New York and Geneva.

31. Mental Health Commission of Canada 2016, Advancing the Mental Health Strategy for Canada: A Framework for Action (2017-2022).

32. GSS, GHS, Macro, ICF (2009) Maternal Health Survey 2007, Accra, Ghana: GSS and GHS; and Calverton, MD, USA: Macro International. Accra, Ghana: GSS.

33. UNICEF (2016) Female Genital Mutilation/Cutting: A Global Concern UNICEF, New York.

34. WHO (1998) Female genital mutilation: an overview. Geneva: World Health Organization, pp: 1-71.

35. WHO (2005) The world health report: make every mother and child count. Geneva: World Health Organization.

36. WHO (2006) Female genital mutilation and obstetric outcome: WHO collaborative prospective study in six African countries', World Health Organization, The Lancet 367: 1835-1841.

37. WHO (2016) WHO guidelines on the management of health complications from female genital mutilation', World Health Organization.

38. Jones GA, Chant S (2009) Globalising initiatives for gender equality and poverty reduction: Exploring failure with reference to education and work among urban 
youth in The Gambia and Ghana. Geoforum 40(2): 184196.

39. Adu J, Tenkorang E, Banchani E, Allison J, Mulay S (2018)
The effects of individual and community-level factors on maternal health outcomes in Ghana. PloS one 13(11): 1-16.

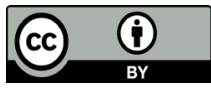

